\title{
Simultaneous Control of Au Nanotube Lengths and Pore Sizes with a Single Kind of Polycarbonate Membrane via Interfacial Deposition at the Air/Water Interface
}

\author{
Myoungho Pyo, Jungsook Joo, and Youn Su Jung \\ Deparment of Chemistry, Sunchon National Lnversity, Chomam 540-742, Korea. ${ }^{*}$-mail: mhodaschuack \\ Received Harch 12, 2007
}

\begin{abstract}
$\mathrm{Au}$ was electrolessly deposited on polycarbonate (PC) membranes $(0.1 \mu \mathrm{m}$ pores) at the air/water interface. It was found that the All nanotube dimension can be controlled by adjusting the plating temperature and the solution composition. Interfacial deposition of All at relatively low temperatures $\left(4^{\circ} \mathrm{C}\right)$ produced long nanotibes. which run through the whole membrane thickness with small openings. Increase of plating temperatures resulted in the decrease of nanotube lengths and Au film thicknesses. It was also disclosed that the inside-diameter of Au nanotubes can be controlled with negligible variations in length by changing the composition of a plating solution.
\end{abstract}

Key Words : PC membrane, Au nanotube. Electroless deposition, Interfacial deposition

\section{Introduction}

Since the preparation of nanostructures through a templateassisted method is relatively straightforward and easy to scale-up. various nanoporous templates have been utilized for the construction of hollow nanotubes or solid nanorods of well defined dimensions over the last decades ${ }^{1-6}$ Templates include inorganic materials such as anodized aluminum oxides $^{7}$ and zeolites. ${ }^{8}$ organic materials such as track-etched PC membranes ${ }^{9-12}$ and regularly ordered polymers. ${ }^{13}$ and biological materials. ${ }^{14}$

Template-assisted synthesis of a variety of nanostnuctures via electrochemical and chemical methods has been reported ${ }^{1-3.5-6.13}$ As a result one can now routinely constrain the growth of desired materials such as metals. semiconductors. and insulators within template channels. Although the electrochemical method has advantages for some cases such as the preparation of segmented nanowires of different components by a sequential deposition. ${ }^{12.15}$ it appears that the electroless deposition has been preferred since it does not require metallic coating for electrical contact. In the chemical deposition. the variation of plating times makes it possible to finely control the pore diameter of nanotubes. Complete filling of template channels is also possible by lengthening the reaction time. ${ }^{9}$ Utilizing track-etched PC membranes as a template. Martin et al. reported various experimental results demonstrating selective transport properties by controlling inside-diameters and surface properties of Au nanotubes. ${ }^{69-1]}$ However. simultaneous control of the length and the pore size with a single kind of membrane was impossible as the length of nanotubes is strictly determined by the membrane thickness.

This paper addresses electroless deposition of $\mathrm{Au}$ on track-etched PC membranes at the air/water interface. The formation of Au nanotubes of various lengths and insidediameters by adjusting plating temperatures and solution compositions is demonstrated

\section{Experimental}

Commercially available PC membranes of $0.1 \mu \mathrm{m}$ pore diameters (nominal thickness $=6 \mu \mathrm{m}$. pore density $=4 \times 10^{8}$ $\mathrm{cm}^{-2}$. SPI-Pore ${ }^{\mathrm{TM}}$ ) were used as a template. Besides floating membranes on a Au plating solution. Au depositions were carried out via the same procedure as described previously by others ${ }^{\text {ti }}$ Briefly. membranes were sensitized with a methanol/ $\mathrm{H}_{2} \mathrm{O}\left(50 / 50\right.$. v/v) solution of $0.026 \mathrm{M} \mathrm{SnCl}_{2}$ and $0.07 \mathrm{M}$ $\mathrm{CF}_{3} \mathrm{COOH}$ for $15 \mathrm{~min}$. After thorough washing with methanol and water. dried membranes were floated on an ammoniacal $\mathrm{AgNO}_{3}$ solution for $30 \mathrm{sec}$ to yield Ag nanoparticles on membrane faces and pore walls. After washing with copious amounts of water. membranes were dried at ambient overnight. Membranes were then carefully floated on an aq. solution of $7.9 \mathrm{mM} \mathrm{Au}^{-}$(diluted from a conmercial Au plating solution. Oromerse SO Part B. Techuic. Inc.) and $0.127 \mathrm{M} \mathrm{Na}_{2} \mathrm{SO}_{3}$ (Aldrich). Maintaining temperatures constant. $\mathrm{HCHO}$ was added to be $0.625 \mathrm{M}$ and the reaction proceeded for 15 lurs Membranes were then dipped in a $c a$. $20 \% \mathrm{HNO}_{3}$ solution for $6 \mathrm{hrs}$ and heat-sealed at $150^{\circ} \mathrm{C}$ for $12 \mathrm{hrs}$.

Permeation tests were performed in an H-cell. One compartment was loaded with a solution of $0.1 \mathrm{M}$ methyl viologen $\left(\mathrm{MV}^{-}\right)$dichloride and $0.1 \mathrm{M} \mathrm{NaCl}$ and the other with a $\mathrm{MV}^{2+}$-free solution of $0.1 \mathrm{M} \mathrm{NaCl}$. Permeation of $\mathrm{MV}^{-2}$ with time was electrochemically monitored utilizing a potentiostat (EC Epsilon) equipped with a Au button (working. geometrical area $=0.02 \mathrm{~cm}^{2}$ ), a Ag wire (reference), and a Pt plate (counter).

Au nanostructures were examined by contact-mode atomic force microscopy (Nanoscope E. DI). scanning electron microscopy (JSM T-330A. JEOL), and field emission scanuing electron microscopy (XL30S FEG Philips).

\section{Results and Discussion}

Au deposition on $\mathrm{PC}$ membranes at the interface was 
carried out at 4, 25, 50, and $75^{\circ} \mathrm{C}$. After Au deposition, the solution-contacting face $(\mathrm{SCF})$ of membranes exhibited visual similarity with a typical color of $\mathrm{Au}$ regardless of the deposition temperature, but the air-contacting face $(\mathrm{ACF})$ became dark brown from yellowish brown as the temperature was increased from $4{ }^{\circ} \mathrm{C}$ to $75^{\circ} \mathrm{C}$. In addition, the electric conduction along with $\mathrm{ACF}$ was observed only for the membrane made at 4 " $\mathrm{C}$. The other 3 samples showed no electric conduction. However, it does not mean that $\mathrm{ACF}$ of the membrane made at $4{ }^{\circ} \mathrm{C}$ was fully covered with a Au filın. After removing the Au film of SCF by mechanically polishing with an ethanol-wetted cotton swab, the electric conduction along with $\mathrm{ACF}$ was no longer observed, indicating that $\mathrm{Au}$ was not deposited on $\mathrm{ACF}$. This was further confirmed by the fact that $\mathrm{ACF}$ of all 4 samples required metallic coating for scanning electron inicroscopy (SEM) measurements. These color and conductance differences suggest that the dimension of Au nanostructures prepared at the interface is influenced by the plating temperature. It should be mentioned that, as far as Au deposition is carried out at the interface, pretreatments (sensitization and $\mathrm{Ag}$ particle formation) of membranes either by floating on or dipping in solutions give the identical results.

In order to compare the extent of $\mathrm{Au}$ deposition within pores, the Au-coated membranes were placed in aqueous solutions of $0.1 \mathrm{M} \mathrm{NaCl}$ and capacitances measured from cyclic voltammograms (CVs) at $0.1 \mathrm{Vs}{ }^{1} \cdot{ }^{16}$ Au surface areas per unit area of membrane face (no pore wall area was included.) were sumınarized in Table l. Considerably greater surface areas than $1.0 \mathrm{~cm}^{2}$ for all samples indicate that nanotubes, rather than nanorods, were produced. If nanorods were formed. Au surface areas should be about $1.0 \mathrm{~cm}^{2}$ irrespective of the deposition temperature. large variations of the surface area suggest again that the length and/or the inside-diameter of Au nanotubes depend on the deposition temperature.

In order to examine the surface feature of Au-deposited membranes without metallic coating. we utilized contactAFM instead of SEM. rigure I shows AFM images of ACF and $\mathrm{SCF}$ (denoted by subscript $\mathrm{a}$ and $\mathrm{s}$, respectively) of $\mathrm{Au}$ coated membranes at (A) 4, (B) 25, (C) 50, and (D) $75^{\circ} \mathrm{C}$. Besides $1 A_{a}$, AFM images of $I B_{a}, I C_{a}$ and $1 D_{3}$ show similar pore diameters of $c a .0 .1 \mu \mathrm{m}$. Deviation of $1 \mathrm{~A}_{\mathrm{a}}$, exhibiting slightly smaller pore diameters, is due to nanotubes reaching $\mathrm{ACF}$ as mentioned above. AFM images of $\mathrm{SCF}$, on the other hand, indicate that the pore diameter becomes greater as the
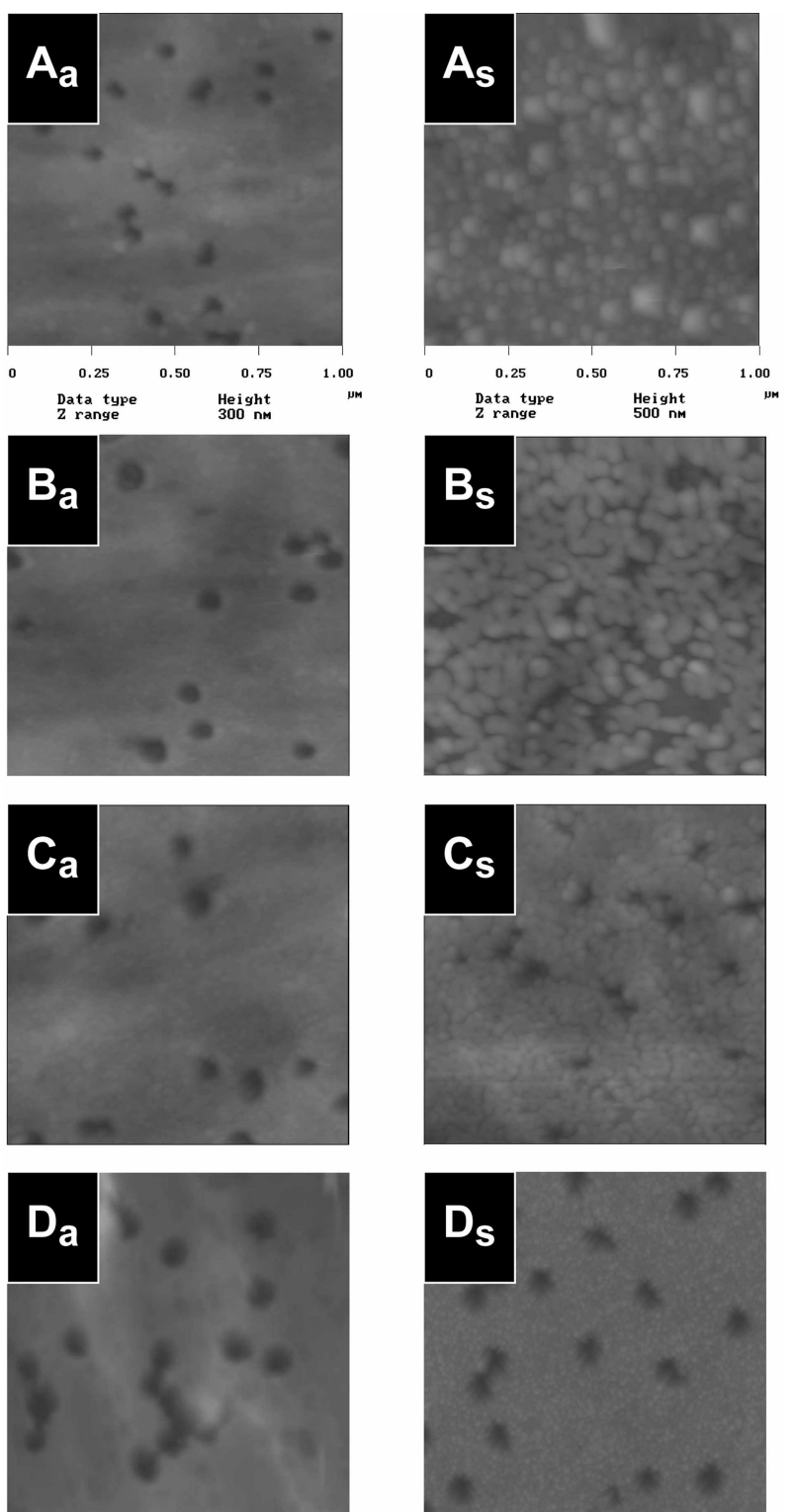

Figure 1. Contact-AFM images of Au-deposited membranes at (A) 4 , (B) 25, (C) 50. and (I) $75^{\circ} \mathrm{C}$. Subseripl a and s indicale $\mathrm{ACF}$ and $S C l$. respectively:

increase of deposition temperatures. While the pores seem to be clogged at 4 " $\mathrm{C}\left(1 \mathrm{~A}_{\mathrm{s}}\right), \mathrm{SCl}$ of a Aut-deposited membrane at $75^{\circ} \mathrm{C}$ exhibits the opening of $c a .40 \mathrm{~nm}\left(1 \mathrm{D}_{\mathrm{s}}\right)$.

Although the difference of pore openings of SCF suggests the possibility of a thin film formation with raising the

Table I. Au surface areas and nanotube dimensions prepared at the interlace

\begin{tabular}{|c|c|c|c|c|c|}
\hline \multirow{2}{*}{$\begin{array}{c}\text { Au deposition } \\
\text { temperature } \\
\left({ }^{\circ} \mathrm{C}\right)\end{array}$} & \multirow{2}{*}{$\begin{array}{l}\text { "Capacitance }(\mu \mathrm{F}) \\
\text { unit area of membrane } \\
\text { face }\left(\mathrm{cm}^{2}\right)\end{array}$} & \multirow{2}{*}{$\begin{array}{l}\text { "Au surface arca }\left(\mathrm{cm}^{2}\right) \\
\text { iunit arca of membranc } \\
\text { face }\left(\mathrm{cm}^{2}\right)\end{array}$} & \multicolumn{2}{|c|}{ 'Alu nanotube dimension $(\mu \mathrm{m})$} & \multirow{2}{*}{$\begin{array}{c}\text { "Roughness of Au } \\
\text { Jilms }\end{array}$} \\
\hline & & & l.ength & Pore size & \\
\hline 4 & 311 & 14.8 & 6.4 & 0.020 & 5.7 \\
\hline 25 & 202 & 9.6 & 2.2 & 0.042 & 4.4 \\
\hline 50 & 133 & 6.3 & 1.4 & 0.054 & 3.2 \\
\hline 75 & 64 & 3.0 & 0.7 & 0.067 & 1.9 \\
\hline
\end{tabular}

"Double layer capacilance was measured from $\mathrm{CV}_{s}$ in $0.1 \mathrm{M} \mathrm{NaCl}$ at $0.1 \mathrm{VS}$ '. "Au capacitance of $21 \mu$ tem " was used. "r.soblaited from $\mathrm{SEM}$ and FF:SF:M images of Figure $3 . "$ roughness = ( Au surface arca calculated from capacitance)/(geonctrical area calculated from dimension) 

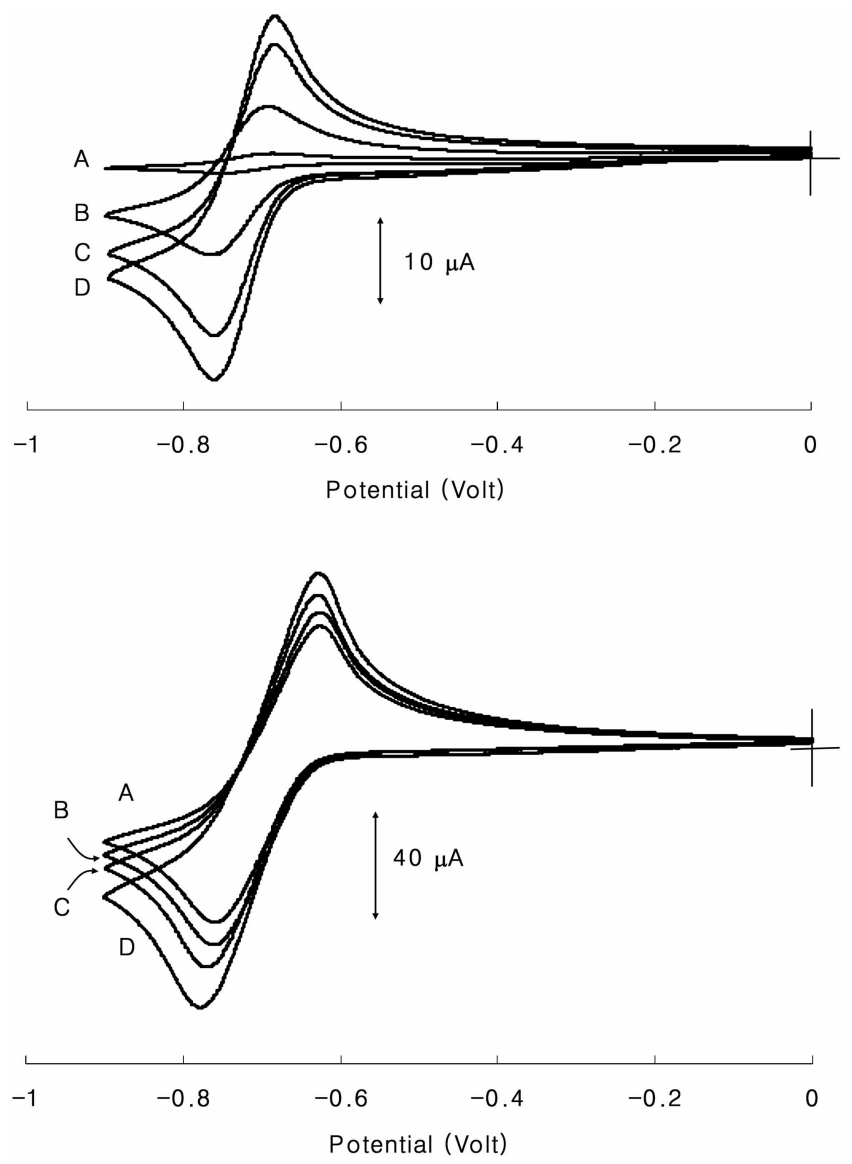

Figure 2. C $\mathrm{Vs}$ of $\mathrm{MV} \mathrm{V}^{21}$ diflused, from a solution containing $0.1 \mathrm{M}$ $\mathrm{MV}^{21}$ and $0.1 \mathrm{M} \times \mathrm{CaCl}^{\prime}$ to $\mathrm{MV}^{2}$-free $\mathrm{NaCl}$ solution. through $\mathrm{Au}$ nanotubes prepared at (A) 4. (B) 25. (C) 50, and (D) $75^{\circ} \mathrm{C}$ (top) before and (botlom) atler removal of a $\mathrm{Au}$ Lilm on SCF: Scan rate $0.1 \mathrm{Vs}^{-1}$.

deposition temperature, it does not necessarily mean that the inside-diameter of nanotubes also varies with temperatures. In order to tackle this point, we compared the amounts of $\mathrm{MV}^{2+}$ permeated through membranes before and after removal of Au films on SCF. Figure 2 (top) shows CVs of $\mathrm{MV}^{2+}$ permeated for $6 \mathrm{hrs}$ through as-made membranes. It is not surprising that the redox peak heights of $\mathrm{MV}^{2-}$ increase from $\mathrm{A}$ to $\mathrm{D}$ since the amounts of $\mathrm{MV}^{2-}$ permeated is directly related to the pore openings of $\mathrm{SCr}$. This was compared with $\mathrm{CVs}$ of $\mathrm{MV}^{2-}$ permeated through membranes with bare SCF (Figure 2 (bottom)). Although the peak heights exhibit similar trends, the amounts of $\mathrm{MV}^{2+}$ are considerably greater than those with as-made membranes. Note the difference of current scale in Figure 2. Significant increase of the amounts of $\mathrm{MV}^{2+}$ implies that preferential deposition of Au on SCF occurs, but does not affect the inside-diameter of nanotubes even in the vicinity of $\mathrm{SCF}$. lhis behavior is different from the result addressed by Yamada et al..$^{17}$ who showed that a Au film with a uniform thickness is formed during electroless Au deposition in a solution.

In order to directly compare the length of nanotubes, SEM images were taken after dissolving out $\mathrm{PC}$ by carefully
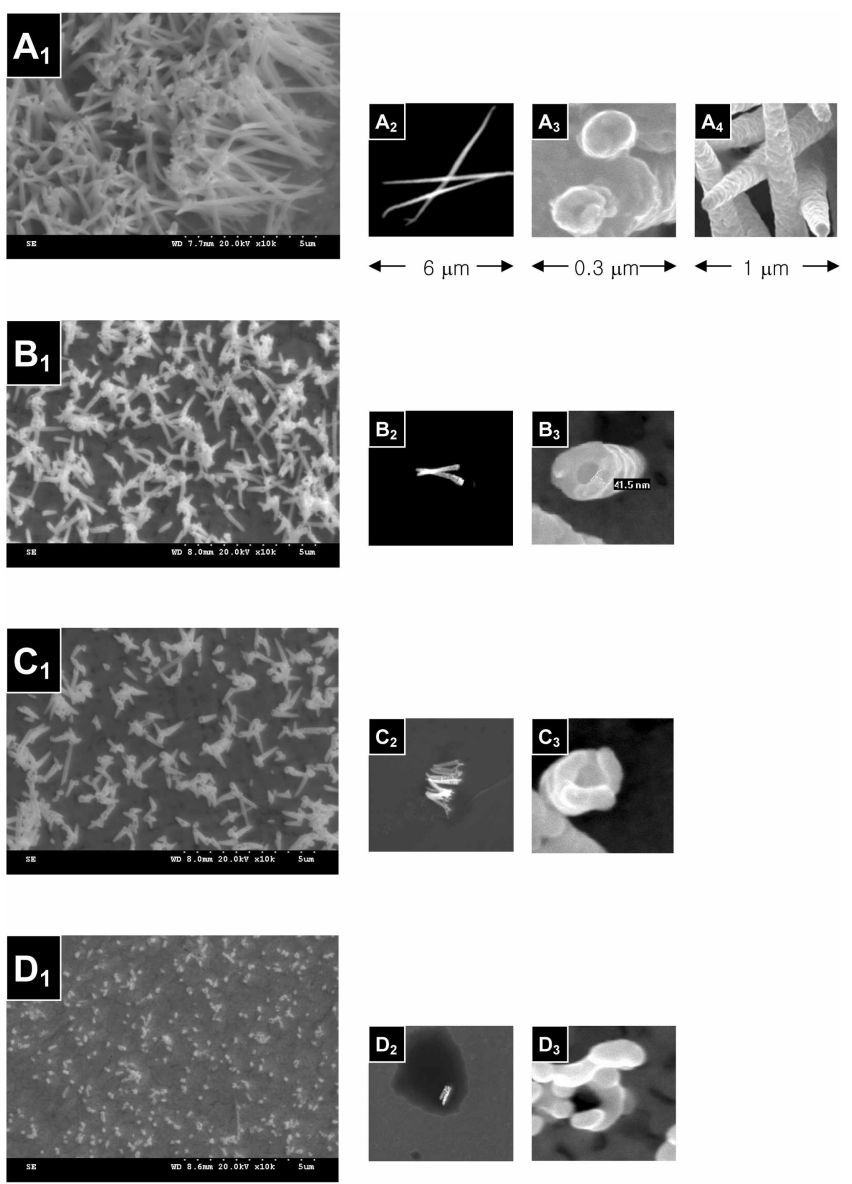

Figure 3. SEM and FESEM images of Au nanotubes prepared at (A) 4. (B) 25 , (C) 50 . and (D) $75^{\circ} \mathrm{C}$.

dropping $\mathrm{CH}_{2} \mathrm{Cl}_{2}$ onto $\mathrm{ACF}$. Figure $3 \mathrm{~A}_{1}-3 \mathrm{D}_{1}$ show that the deposition temperature greatly affects the length of nanotubes. Interfacial deposition at $4{ }^{\circ} \mathrm{C}$ produces the longest nanotube, which appear to line the whole pore walls. The increase of the deposition temperature results in the reduction of the length. This behavior can be seen more clearly, in Figure $3 \mathrm{~A}_{2}-3 \mathrm{D}_{2}$, for which $\mathrm{PC}$. membranes were dissolved and ultrasonicated in $\mathrm{CH}_{2} \mathrm{Cl}_{2}$ after mechanically removing a $\mathrm{Au}$ film on SCF. The length of nanotubes prepared at 4, 25, 50 . and $75{ }^{\circ} \mathrm{C}$ was $\left(\mathrm{A}_{2}\right) 6.4,\left(\mathrm{~B}_{2}\right) 2.2,\left(\mathrm{C}_{2}\right) 1.4$, and $\left(\mathrm{D}_{2}\right) 0.7 \mu \mathrm{m}$ respectively. Figure $3 \mathrm{~A}_{2}$ also shows tapered ends which result from cigar-shaped channels of a template. ${ }^{18}$ A FESEM image of tube ends of an $\mathrm{ACF}$ side was illustrated in rigure $3 \mathrm{~A}_{4}$. As expected, nanotubes demonstrate no indication of a $\mathrm{Au}$ film on $\mathrm{ACF}$ as well as a tapered structure. The pore size of nanotubes was also examined. FESEM images in Figure $3 \mathrm{~A}_{3}-3 \mathrm{D}_{3}$ show that the diameter of openings is increased from (A) $c a .0 .020 \mu \mathrm{m}$ to $c a$. (B) 0.042. (C) 0.054 , and (D) $0.067 \mu \mathrm{m}$. Note that the outside-diameters of nanotubes of Figure $3 \mathrm{~B}_{3}, 3 \mathrm{C}_{3}$, and $3 \mathrm{D}_{\mathrm{s}}$ are greater than $0.1 \mu \mathrm{m}$.

The dimension of the nanotubes was summarized in lable 1. Utilizing the inside-diameter and the length in Table 1 along with a nominal pore density of $4 \times 10^{8} \mathrm{~cm}^{-2}$ of a $\mathrm{PC}$ membrane, the geometrical area of $\mathrm{Au}$ was calculated. The geometrical area per unit area of a membrane face was 


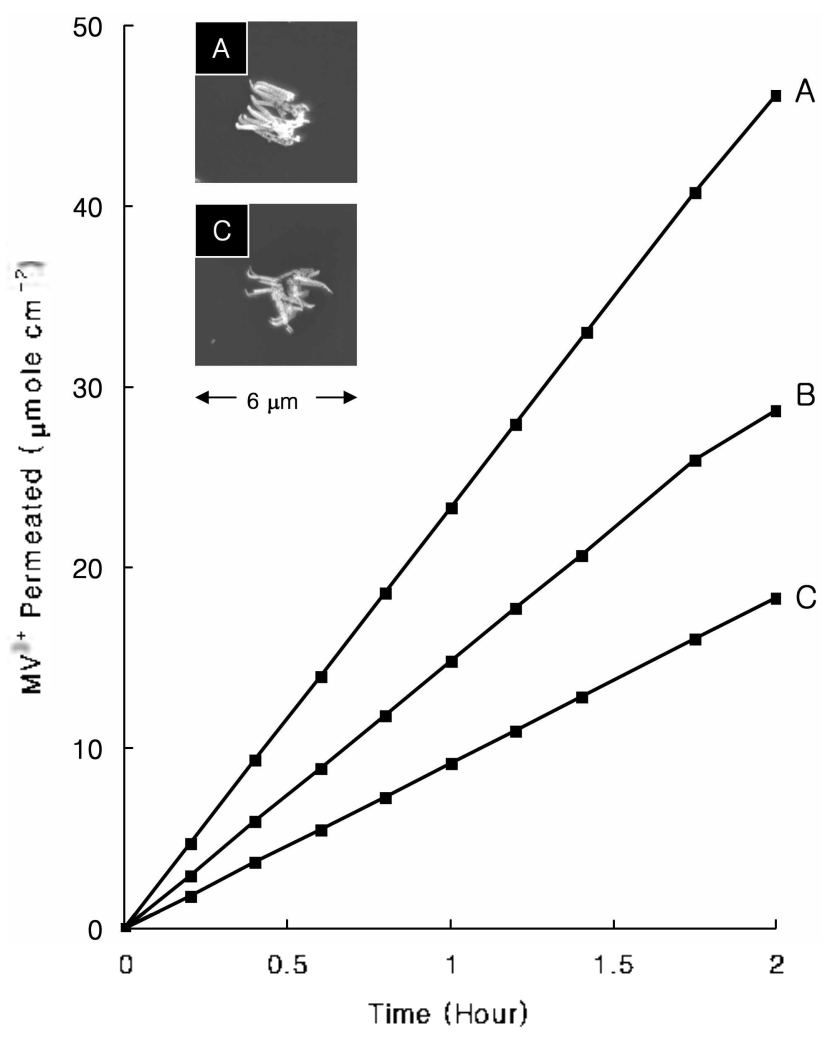

Figure 4. Amounts of $\mathrm{MV}^{2+}$ permeated through $\mathrm{Au}$ nanolubes prepared on solutions of $\left[\mathrm{Au}^{-}\right\rceil=(\mathrm{A}) 32$. (B) 7.9 . and (C) $4.0 \mathrm{mM}$ at $25^{\circ} \mathrm{C}$. Insets show corresponding SEM images of nanotubes. For a SF.M image corresponding to $B$, refer to $B_{2}$ of Figure 3 .

decreased from $2.6 \mathrm{~cm}^{2}$ at $4{ }^{\circ} \mathrm{C}$ to $2,2,2,0$, and $1.6 \mathrm{~cm}^{2}$ as the increase of deposition temperature. The roughness of $\mathrm{Au}$ (i.e., the ratio of the surface area obtained from capacitance to the geometrical area) was listed in the rightmost column of Table 1. Reduction of the surface roughness of Au films at relatively high temperatures corresponds to the smooth surfaces shown in Figure $1 C_{S}$ and $\mathrm{ID}_{\mathrm{s}}$.

The control of the inside-diameter of nanotubes, keeping the length variation minimized, is also possible by adjusting $\mathrm{Au}^{+}$concentrations of a plating solution. Au films on $\mathrm{SCF}$ were removed after deposition and cathodic peak currents of $\mathrm{CVs}$, due to $\mathrm{MV}^{2-}$ permeation, were monitored with time. l'eak currents were converted to the concentration of $\mathrm{MV}^{2+}$ by using the Randles-Sevick equation. Figure 4 shows the amounts of $\mathrm{MV}^{2+}$ permeated through nanotubes prepared in $\left[\mathrm{Au}^{+}\right]=(\mathrm{A}) 32$. (B) 7.9 , and (C) $4.0 \mathrm{mM}$ at $25^{\circ} \mathrm{C}$. It is obvious that the diffusion of $\mathrm{MV}^{2-}$ becomes more hampered through the nanotube prepared in a more diluted solution of $\mathrm{Au}^{+}$. Since the SEM images indicate the similar nanotube length (insets in Figure 4), the differences in the amounts of
$\mathrm{MV}^{2-}$ are ascribed to the decrease of the pore size with a dilution of $\left[\mathrm{Au}^{-}\right]$.

\section{Conclusions}

Deposition of $\mathrm{Au}$ at the interface produces the nanotube of various lengths and pore sizes, controlled by the temperature and the concentration of $\mathrm{Au}^{-}$. indicating that the preparation of Au nanotubes of various dimensions with a single kind of template is possible. As the increase of plating temperatures. interfacial deposition results in the formation of long nanotubes with small pores. Minimizing the length variation. the inside-diameter of nanotubes can also be controlled by adjusting the concentration of $\mathrm{Au}^{-}$.

Acknowledgment. This work was supported by the Korea Research Foundation Grant funded by the Korean Government (MOEHRD, Basic Research Promotion Fund) (KRF-2006$521-(00080)$.

\section{References}

1. Hernandez-Velec. M. Thin Solid Films 2006. 495. $5 \mathrm{I}$

2. Sung. I). D.: Choo. M. S.: Vot. I. S.: Chin. W. B.: Yang. W. S. Bufl. Korean Chent. Soc, 2006. 27.1159.

3. I. . C. Bull. Korew Chem Soc, 2006. 27.991.

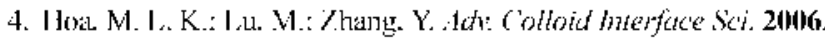
121,9.

5. Diaz. D. J.: Willianson. I. L.: Gua. X.: Sood. A.: Bohn. P. W. Thin Solid Films 2006. 5/4. 120

6. Harjoll. C. C.: Lec. S. B.: Martin. C. R. And. Chem. 2003. 75. 6861.

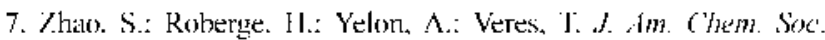
20106. 128. 12352.

8. Yang. L.: Xia. Y.: Sun. X.: Mokaya. R. J. Phys. Chem. B 2006. 110. 18424 .

9. Nishizawa. M.: Menon. V. P.: Martin. C. R. Science 1995. 268. 700 .

10. Martin. (. R.: Nishizawa. W.: Jirage. K.: Kang. M. J. Phy (hem. B 2001. $/ 115.1925$

11. Gasparac. R.: Mitchell. D. I:: Martin. C. R. Electrochim. At'ts 2004. 19.847

12. Rancs. 0.: Demoustier-Champagnc. S. J. Electroctem. Soc. 2005. 152, D130

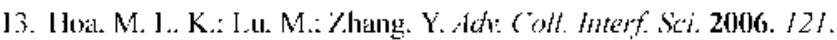
9

14. Zhang. B. J.: Davis. S. A.: Mendelson. N. H.: Mann. S. Chem. Conmitu. 2000. 9.781.

15. Park. S.: Lim. J.-H.: Chung. S.-W.: Mirkin. C. A. Scrence 2004. 30,348 .

16. Menon. V. P.: Martin. C. R. Intt (hem. 1995. 67. 1920.

17. Yamadia. K.: (jacsparec. R.: Martin. C.. R. I. Electrochem. Soc. 2004. 15/.Ẻ14.

18. Apcl. P. Yu.: Blonskaya. I. V.: Dmitrick. S. N.: Orclovitch. O. L.: Sartowska. B. J. Nenbr: Sei. 2006. 28.2. 393 